\title{
QUALITY REQUIREMENTS IN THE FORESTS OF THE FUTURE
}

\author{
By S. G. REID and J. L. LADELL ${ }^{\text {I }}$
}

\begin{abstract}
$S U M M A R Y$
World demand for paper is growing rapidly. Although Canada will continue to be the leading exporter of paper in the immediate future, there will be increasing competition from fast growing man-made forests of the tropics and subtropics. Competition from non-cellulose materials will also increase. To meet these challenges, the quality of Canadian pulp and paper products must be improved while keeping costs to a minimum.
\end{abstract}

The conventional methods of pulping have been tuned up to a high pitch, and virtually any species can now be utilized. The paper maker, by manipulating his raw material and by the use of additives, can produce paper with widely different properties; but such operations add to costs, and the closer the raw material approaches to the paper maker's requirements, the lower these costs will be.

Although the manner in which fibre characteristics influence paper properties has been studied for a number of years, little of this work can be directly related to Canadian species, about which we need to know a lot more.

With increasing knowledge of the properties of our different species and the ability of the pulp and paper technologist to use each efficiently, it is suggested that the emphasis will shift to maximum economic production of wood substance in terms of weight, as opposed to production by volume of merchantable wood. This will likely bring changes not only to our concept of the 'ideal tree', but also in the management of forests and silvicultural treatment of stands. Utilization of tops and branches in certain cases must also be given serious consideration. In addition to low cost cellulose, Canada must continue to produce a proportion of top quality fibres such as those of the northern spruces.

Much of the above can be applied to the sawmill industry where low costs and high quality are again the key requirements.

In the future the forester will be called upon not only to plan and tend the forests; he must also take complete responsibility for delivery directly to the mill, sawmill or factory, according to a master plan, of material of a pre-determined character.

World consumption of paper and paperboard has increased over the years to the present record level of around 95 million tons per year, and an extension of the present growth curve indicates that this figure could be doubled in the next twenty years.

\footnotetext{
'Ontario Research Foundation, Toronto, Ont.
} 
The present per capita annual consumption of paper in the United States is around $450 \mathrm{lbs}$. - the highest in the world. In Canada and Sweden the figure is presently around 300 lbs.; in Japan and European countries other than Sweden, around 100 to $200 \mathrm{lbs}$.; in South American countries, South Africa, and the U.S.S.R., around $40 \mathrm{lbs}$.; in the other Asiatic countries, around $4 \mathrm{lbs}$.; and in other African countries, around $2 \mathrm{lbs}$. Obviously the potential for increased use of paper throughout the world is huge. Historically the increase in paper usage in any country has followed a fixed pattern: so long as the country remains undeveloped, paper usage is extremely low; as development proceeds, paper usage creeps up very slowly until the standard of living is quite high, then per capita paper consumption increases rapidly to a high level. At this moment a large number of countries are at the stage where the standard of living is rising rapidly.

Over the years, Canada has prospered as a pulp and paper exporter, easily the largest in the world, and, at this moment, these exports are rising and a huge expansion of pulping capacity is underway.

Prospects are bright, but we dare not sit back and take it easy. Other countries have large natural forests which may readily be tapped. One thinks of Russia and, for example, Brazil where a market pulp industry is now being built up. Also of importance, in various parts of the world man-made forests are coming into being at an ever-increasing rate. After the last war, there was a spate of planting in the southern United States, Australia, South Africa, and in Europe. These plantations are now reaching maturity and are being cropped. Recently, South Africa and New Zealand have started to export pulp. A field survey of Commonwealth countries in Africa and Central America is now getting under way, with a view to the selection of suitable species for the establishment of fast growing plantations in these countries. There can be no doubt that eventually huge man-made forests will also arise in the countries of Asia. It is, therefore, important that we should, at this time, be especially careful in providing for the future. Canada's vast acres of natural forest, while reassuring to contemplate, must not become a source of complacency.

The new forests of the tropics and subtropics are fast growing. In some parts of the world, rotations are as short as 10 or 15 years. It might be said that, although Canada, in contrast, has to make do with much longer rotations, this disadvantage is offset by the much larger store of wood that is available. But this is not entirely correct because, with very short rotations, it is possible to supply a pulp mill from a relatively small area in perpetuity, theoretically, with harvesting costs kept low by short haulage distances and a permanent system of extraction roads. Where rotations are long, the total forest area must increase, distances increase, and so transport difficulties and harvesting costs mount. The struggle to keep costs low in the Canadian pulp and paper industry is intensifying and will grow more acute as time goes by. It is not without significance that the pulp and paper companies in Canada are among the leading practitioners of mechanization at the present time.

In addition to competition from other pulp producing countries which could affect us directly as pulp exporters, there is an even more fundamental problem looming for all producers of pulp and paper. This is the challenge 
of competitive materials, particularly plastics. Polyethylene production in North America is setting new records every year, and the cost to the trade has fallen to about 15 to 20 cents per pound, compared with 6 to 10 cents for pulp fibres. Polyethylene, because of its special qualities, has already taken over from paper in a number of fields such as fertilizer bags, produce sacks, and garment bags, and is threatening shipping containers and cartons. Polyethylene usage has grown also at the expense of wax paper, parchment paper, and cellophane; and other non-celluloses have made inroads into rayon and viscose areas. One even hears talk of extremely cheap foamed plastic sheeting which prints and handles just as well as newsprint.

This process of replacement of raw materials is, of course, a progressive one with, for example, the wire-bound wooden box being replaced by the corrugated paperboard carton, and this in turn being threatened by plastic containers. Salvation lies in improving the quality and design of paper products to better the competition, and in the opening of new fields for paper, such as through combination with plastics and foils. The development of a truly water resistant paperboard, for example, would result in the opening up of extensive markets in the field of prefabricated shelters. In Canada, more research of this kind is needed, and, at the same time, we do urgently need to know more about the design requirements of paper products so that we can eliminate wasteful over-engineering.

It is a fact that the major requirement for any product is high quality, i.e., the product must have properties which are eminently satisfactory for the purpose in hand. If the buyer feels that a polyethylene bag can do a particular job better than a paper bag, and the cost is right, the paper bag will be replaced.

So the key points in pulp and paper production are quality and cost. We must work constantly to improve quality while keeping our costs competitive. It is not enough just to hold quality constant. Others, in and out of the paper industry, are working steadily to better us. At the moment Canadian pulp is as high in quality and as low in cost as the competition, but this may not always be so.

The question is: what can we do now to meet these challenges? Let us turn first to the processing end of the business and see what is being done there to improve quality and reduce costs, for what is happening - and what will happen - in the pulp mill must guide the forester in his plans for the future.

Mechanical pulp represents about half of Canadian pulp production. Pulp produced by the traditional stone grinding method tends to give short, stiff bundles of fibres which result in low sheet strength. The use of a disc refiner fed with chips produces, in general, a pulp with somewhat longer fibres and fewer chunks, while a short chemical pretreatment of the wood prior to refining gives even better results. In these ways a start has been made to improve the quality of newsprint (which contains about $80 \%$ mechanical pulp) to meet the challenge of competitive materials.

The production of newsprint in the southern United States is increasing. At the moment, it is true that many U.S. printers and advertisers prefer Canadian newsprint to the southern product because the thin, flexible spruce 
fibres of the Canadian material give the paper a smoother surface. The southern pine product has excellent strength, but the surface tends to be rough. Needless to say, U.S. pulp producers are working hard on this problem. It must also be mentioned that Canadians producing newsprint for export to the United States, in addition to their technical problems, have to comply with the sometimes irksome requirements of the U.S. Tariff Act.

It is in chemical pulping that chemists all over the world have worked hardest on improving the quality of the final product. Taking the overall view, the historic methods of chemical pulping have been tuned up to a high pitch. Virtually any species can now be cooked by either the sulphite or the kraft method, and the physical properties of the pulps can be varied widely by altering the cooking conditions. Pulp yields can be adjusted to suit the job in hand. The latest "highest-yield" pulps produced by a neutral sulphite semichemical process, are in the $80 \%$ yield bracket and are ideal as the fluting medium in corrugated paper. At the other extreme, yields of around half that figure must be accepted if the pulp is to be used for rayon or cellulose acetate production.

The big expansion of chemical pulping being planned in Canada at the moment is in kraft pulping, mostly on the West Coast. This expansion is intended to take care of increasing world-wide demands for high quality, strong pulps as opposed to run-of-the-mill pulps which are relatively easy to produce and are in good supply. The continuous kraft system has been chosen as the best method of meeting this need. In order to be economic, a kraft mill producing market pulp must be large, probably making in excess of 600 tons of pulp per day, and this calls for a very large capital investment and a very large wood supply, hence the interest in British Columbia.

At present, in chemical pulping research circles, interest is centred on ways in which fibres can be isolated from wood with less damage to the cellulose chains. Ways in which the attendant hemicellulose sugars can be retained with the cellulose, or released at will, are also being developed. There is, in addition, a great need for speeding up the pulping process, thereby effectively reducing size of equipment and cost. Real progress in this direction has already been made in the recently announced Alkafide continuous pulping process developed by the Pulp and Paper Research Institute of Canada and Dominion Tar and Chemical Company Ltd.

With regard to improvement in product quality at the paper machine, one enters a complex area. The paper maker has at his beck and call, pulps from different regions (and countries) containing different wood species, cooked to different yields by several different methods, and bleached to different extents. From these, he undertakes to produce efficiently a sheet with a specified density, basis weight, opacity, brightness, stiffness, surface finish, absorbency, burst, tear, fold and tensile strength - and, in addition, its appearance has to be good or the user will not like it. Not long ago, in Canada and the United States, softwoods were universally available and could be pulped easily, so pulps from these were used exclusively. Then in many areas softwood became more expensive, and hardwoods had to be pulped. The interesting thing is that papermakers have grown to like the special properties of this material they were forced to use, and now say that 
they could not manage without it. While the strength of the short-fibre hardwood pulp is low, inclusion in a paper furnish gives improved sheet formation and smoothness, and improved printing surface, and high bulking. Many companies now call for around one-quarter of their wood requirements in hardwood, and in Japan, the third largest producer of paper and paperboard after the United States and Canada, there has been an attempt made to use strong softwood fibres only where they are really required, so that now approximately one-half of the pulp used there is from hardwood.

In addition to choice of pulps and the amount of refining to which he subjects the pulps, the paper maker has available an ever-increasing arsenal of chemical additives. These he uses to make up for short-comings in the pulps, or for special effects. With them he can build in wet strength, water repellency, higher brightness, higher strengths, and many other qualities which are lacking in the original material. So the paper maker has a choice: he can achieve a strong, bright sheet by using high quality bleached pulp, or he can achieve the same results starting with a lower quality pulp and adding special chemicals. These chemicals are often costly; it is all a matter of economics.

At the very heart of the problem of improving the quality of products made from cellulose fibres is the need for a better understanding of how the characteristics of the constituent fibres play their role in the achievement of the desired properties in a sheet of paper.

The basic process of paper making is the simple one of reducing wood to its component fibres and laying these fibres from a water slurry into the form of a mat which, when pressed and dried, becomes the sheet of paper. The nature and source of the strength of such a sheet has been the subject of research and controversy for many years.

The phenomenally high tensile strength of individual wood fibres was demonstrated early in this century and has been repeatedly verified. The magnitude of the strength of the individual fibres compared with that of a sheet of paper led to the belief that the strength of paper must be governed solely by the strength of the inter-fibre bonds, and it was not until as late as 1958 that it was established that mechanical failure of paper did involve rupture of fibres as well as the breaking of inter-fibre bonds. (VAN DEN AKKER et al. 1958).

More recently, in a generalized theory NISSAN et al. (1964) have concluded that, in a sheet of paper, the same kind of intermediate-strength bonds (termed hydrogen bonds) predominate in both between-fibre and within-fibre bonding and that the strength of the sheet will depend on the weakest links. If fibre-to-fibre contact (and therefore bonding) is poor, as in low-density paper, the weak links will lie at the fibre interfaces; but if fibre-to-fibre bonding is good, as in higher density paper, breakage of the actual fibres will occur. The breakage will take place at points of weakness in the fibres arising from damage during processing, or from innate flaws in the fibres from a particular tree or species, or from a combination of the two.

One then has a picture of paper making in which thick-walled fibres resist collapse upon mild beating and retain their tubular shape to give a bulky sheet of low density. Since fibre contact is poor, fibre-to-fibre bonding will also be poor, and this results in a sheet with low tensile strength and relatively high 
tear strength. Conversely, if thin-walled fibres are used, even without expenditure of much energy on beating, these will collapse to flat ribbons giving a dense paper sheet with large areas of the fibre surfaces in contact. Such paper will have high tensile strength but low tear strength. Prolonged beating of thick-walled fibres renders them more flexible, and the paper sheet made from these will have gained tensile strength at the expense of tear strength.

The exact manner in which fibre characteristics influence paper properties has been the subject of study during which many controversies have arisen, because none of the variables is independent, and the interpretation of results is extremely difficult. To quote some recent work: tensile strength per unit cross section of cell wall material has been shown to correlate positively with paper tensile strength for six American hardwoods (KELLOGG and WANGAARD, 1964) and for slash and loblolly pines (EINSPAHR, 1964). In agreement with Nissen's theory mentioned earlier, the positive relation of fibre strength and paper tensile strength was particularly good for highly-beaten, dense paper, in which fibre bonding is good and breakage of fibres is expected to occur. In the work on slash and loblolly pines it was also shown that fibre strength correlated positively with fibre length, and the author suggested the short cut of selecting trees for improved pulp strength on the basis of fibre length.

Fibre collapsibility as measured by cell wall thickness in relation to lumen diameter has also been shown experimentally to be important in paper quality. In a study of loblolly pines, BAREFOOT et al. (1964) selected four trees which covered a wide range of specific gravity and fibre length. Highyield kraft pulp was made from the core and outer wood of each tree, and paper properties such as sheet density, burst, tensile and tear strength were measured. It was shown that a high percentage of the variation of all the paper properties measured could be accounted for in terms of fibre morphology. Of the fibre dimensions, summerwood cell wall thickness was found to be the best single predictor of paper properties. The scanning microphotometer recently developed by the Pulp and Paper Research Institute of Canada (GREEN and WORRALL, 1963) is a useful tool for the measurement of cell wall thickness and related features.

It must be made clear that results obtained to date are based on work carried out on relatively few species. We are a long way from a thoroughly practical solution to the problem of relating fibre and paper properties. This is particularly true of many of our Canadian species, on which quite little research work has yet been done. We would be on very dangerous ground to attempt to apply the results obtained in other countries, with other species, indiscriminately to our own species. In Canada we have much work yet to do.

Turning aside for the moment, we would like to discuss another aspect which bears heavily on the character of the pulp industry of the future. This is the more efficient use of what is generally termed "waste material", interest in which is stimulated by growing economic pressures.

"Waste" falls into two categories: 1) logging and sawmill wastes, and 2) the non-cellulose fraction of the wood which reaches the pulp mill. Taking these in reverse order, approximately one-half of the dry weight of wood is non-cellulosic (i.e. lignin and hemicelluloses), and, in the chemical pulping 
industry, a large part of this material is used only for its calorific value or, worse still, is discharged into waterways. A few companies have developed saleable by-products such as lignosulphonate dispersing agents, vanillin, D.M.S.O. (the new, much publicized pain reliever), yeast, alcohol, acetic acid, etc. Basic knowledge of lignin is increasing, and much greater use of this potentially valuable material will be made in the future.

Sawmill waste is now being utilized successfully by a number of pulp mills in Canada, stimulated by the introduction of improved barking and chipping facilities. Even sawdust can now be cooked successfully using continuous kraft pulping equipment. Bark utilization is still a problem for many, although one company in the United States is producing a type of fibre from its bark. A vast number of interesting chemicals can be extracted from bark, but few have been marketed so far.

By and large, much more use could be made, and probably will be made, of sawmill waste, but it is in the utilization of logging wastes that we visualize the largest savings in future years. Recently, pulping studies have been carried out in Japan on both softwood and hardwood tops and branches. This material had relatively short fibres, and the yield of cellulose was on the low side; nevertheless acceptable paper and fibreboard were produced (YONEZAWA et al. 1959, 1962). The amount of potentially valuable material left on the ground can be very large. In a study at the University of Maine red spruce and red maple trees were pushed over by a tractor, and the trees disassembled and weighed (YOUNG, et al. 1963). It was found that for each 100 lbs. of wood normally marketed, $43 \mathrm{lbs}$. of wood larger than $1^{\prime \prime}$ in diameter was left as logging residue. In a recent paper, STEPHENS (1963) has shown that in a dense 27 year old red pine stand, 20 per cent of the total weight of the tree was contributed by the branches, while less than half the total weight was in the stem wood. You will notice that we are talking in terms of weight and not volume. There is a distinction here which may bear very heavily on the planning of future forests, as we shall see. Figures on the amount of logging waste following woods operations in Canada can be obtained from a recent paper by KEEN (1963). He estimates, for example, that in the cutting of a stand of black spruce averaging 8" diameter at breast height, the weight of slash produced amounts to about 15 tons per acre, 30 per cent of the total weight of such trees being in their tops and branches.

It must be said, though, that there is very little interest in the harvesting of logging wastes in Canada at the moment. This is particularly true of the West Coast where there are substantial reserves of wood. The economics of utilizing logging wastes would, however, be profoundly affected by the introduction of chip pipelines, as advocated by Dr. Thiesmeyer, President of the Pulp and Paper Research Institute of Canada. Appropriate sorting and chipping procedures could result in the utilization of almost the entire tree, with chips from bole and branches, and even perhaps from needles and bark, kept separate, all piped direct from forest to mill.

It seems likely that with increasing knowledge of the properties of different species and the growing ability of the pulp and paper technologist to manipulate his raw material, stress will be placed more and more on the economical production of wood substance - in terms of weight - rather than on the 
production of wood - in terms of volume. Thus, in planning for the pulp forests of the future, we should probably lay heavy stress on the highest possible rate of production of wood substance per acre, concentrating upon faster growing species and seeking out and testing fast-growing hybrids and exotics. In our plantations we should be experimenting with more daring thinning regimes than are presently employed.

At this point, it might be well to re-examine our concept of the ideal tree. For a long time the beau ideal of the forester has been a tree with a long, clean, perfectly cylindrical bole surmounted by a small, narrow crown. One feels that the forester would prefer to dispense with the crown altogether if at all possible; a vain wish that probably underscores the forester's preoccupation in the past with production of saw timber and our ignorance of the degree to which crown size, foliage mass, rate of growth, and type of wood, interact.

The factors affecting the stem form of trees, which were the subject of a review by LARSON (1963), have been a source of argument for some time. Although it has long been known that the crown exerted an influence over the shape of the bole, it is only comparatively recently that the attention of foresters has been directed, for instance by FARRAR (1961), to the practical significance of research seeking to link growth patterns in the bole with the size and shape of the crown. In recent years, there has been an increasing amount of research done on the growth patterns in the bole of the tree in relation to the crown, on tree sizes and foliage mass, and on the effects of pruning on growth. It has been shown, for example, that the width of the annual ring tends to be greater in the vicinity of the living crown, so that a distinction may be drawn between crown- and stem-formed wood, emphasizing the intimate relation between the foliage mass and rate of growth in the bole, and the fact that we cannot tinker with the crown without changing the character of the wood produced. While we need to know more than we do at present about the interaction between crown and bole, it can be suggested that the fast-growing cellulose producing tree of the future will have a much larger crown than is tolerated at present and may differ in several other important respects from the forester's ideal tree referred to above. While stands of the forester's ideal tree may produce the optimum volume of high grade saw timber, they may not necessarily be the most efficient producers of wood substance in terms of weight. For production by weight, stands of relatively wide-spaced, large-crowned, and perhaps even strongly tapered trees may well be what is required.

The shift in emphasis from the production of wood by volume to the production of wood substance by weight would bring in its train quite profound changes in forest management. The length of rotation required to obtain the optimum production by weight from the whole tree, branches included, may turn out to be quite different from that which is intended to produce the optimum volume of what is now called merchantable wood. In this connection, it is of interest to examine KEEN'S (1963) data from which it can be seen that the weight of merchantable wood in, for example, a white spruce with a diameter at breast height of $12 \mathrm{in}$. is roughly equalled by the weight of a 9 in. tree with its top and branches included. It is probable that the most 
economic cutting cycle for production by weight will tend to be shorter than our commonly accepted volume-producing rotations, for a tree tends to display its most vigorous crown towards the beginning, rather than the end, of its life, and in earlier years a sizable proportion of the tree's total weight is in its branches. The change in the proportion of branchwood as the tree ages would, therefore, have to be carefully studied before it would be possible to select the most advantageous rotation length for production of wood by weight.

Producing for weight of wood substance would also exercise an effect on the choice of species. Choosing the right species may be a tricky business. MITCHELL (1964) has recently shown, for instance, that the average specific gravity of a species may be a poor guide to its capabilities in terms of weight of dry matter production. Thus among the 5 southern pines that he compares, spruce pine, though having the lowest average specific gravity, is second only to loblolly in terms of dry matter production per tree because of its inherently faster growth.

While the above remarks relating to forests of the relatively far future may appear bizarre to our minds, we must be prepared to entertain such possibilities. Research and experimentation in forestry is a laborious business, and results are slow in coming because of the very nature of our subject. And because results are slow in coming, we so often find ourselves in urgent need of information today that we cannot possibly obtain in less than 10 , perhaps 20 or more, years. In many fields, an experiment can be planned, set up, completed, and analyzed in a matter of days or even hours, but in forestry, we have to waitwhich is why we as an industry should be, at this time, wide ranging in our ideas and profligate rather than parsimonious in our investment in research.

It is clear that in the future there will be need for a vast supply of cheap cellulose of all types, to provide the main bulk or substance of the world's paper products. Canada must plan now to produce its share of this class of material. In addition to this low cost 'filler' cellulose, Canada must continue to produce as efficiently as possible, top quality fibres such as those of the fast beating northern spruces, which will be required to reinforce and upgrade paper made from the cheaper pulps.

We must push on with the study of fibre characteristics which affect pulp and paper quality. It is essential to have enough knowledge of the fibre characteristics of different woods, their processing, and the relation of both of these to the properties sought in the finished product, to manufacture the best pulp for each purpose. The sooner we have this knowledge to hand, the sooner will the forester be in a position to meet the increasingly stringent requirements of mills of the future, the most important of these requirements being uniform predetermined papermaking performance. By uniformity we do not mean to imply the use of one species exclusively, or even fixed proportions of species, but rather a flow, continually adjusted as to relative amounts of different material so as to give a uniform product.

It will be noted that we have made only passing reference to the sawmill industry. We must admit this is due partly to our own particular interest in pulp and paper, and that we feel we are in deep enough waters as it is. However, much of what we have said about the pulp and paper industry can be applied equally well to the sawmill industry ... competition from other products and rising production costs are leading, must lead, to cheaper and 
more efficient methods of extraction and conversion. As in the pulp industry, mechanization will play an increasingly significant role. The trend that is observable, at least in Eastern Canada, for the disappearance of the smaller sawmill or its absorption by larger concerns, is symptomatic of increasing economic pressures and also of the growing scarcity of suitable timber trees. It seems inevitable that the West Coast will overshadow the East to an increasing extent in the sawmill field, while the East will probably concentrate more and more on the production of specialized products such as veneer and plywood. If these and like specialties are to be developed economically, however, it would seem that now is the time to start growing trees for a specific end use. We return, then, to an earlier theme, the need to produce custom-grown trees; having decided what is required, to select species, to grow and tend them with a specific use in view. To take a case in point, we understand there is increasing interest in this province in poplar plywood. Now is the time for thinking about future sources of supply and considering the possibility of laying down plantations which will ensure the optimum output of veneer logs at the lowest possible cost. We have already suggested that the cellulose producing and timber producing trees of the future may differ markedly in form and characteristics and that the different uses to which crops of these trees will be put will place their management and silvicultural treatment on a quite different basis.

While perhaps we are straying outside our terms of reference, we might suggest that a lot more research be done with the aim of eliminating, or at least rendering less detrimental, the three characteristics of timber which militate against its use: namely, its inflammability, its liability to rot, and its instability in the face of humidity change. The lumber industry in Canada is apparently content to leave most of the research that is being done in these fields to government agencies. A trade-supported laboratory along the lines of the Pulp and Paper Research Institute of Canada would be a tremendously worthwhile investment for the wood-using industry. The man or research group that develops a cheap and simple treatment that will at one stroke render wood flame-proof, rot-proof, and dimensionally stable will revolutionize the industry. Such a treatment is within the realm of possibility, but a possibility that may not be realized unless industry shows more interest in promoting research.

Of course, one of the most important factors, if not the most important factor to which foresters can contribute in the near future, is the control of harvesting costs. By greatly increasing capital investment in woods machinery the direct labour content has been reduced sufficiently to keep harvesting cost relatively constant over the past 10 years in spite of rising wages, longer hauling distances, and less favourable stands. Mechanization must be made even more effective. As processing methods improve, harvesting costs represent a higher and higher proportion of the total cost of the finished product, and this pleases no one.

In the future it is clear that the forester's job will become more and more complex. Not only must he plan and tend the forests, he must also take complete responsibility for delivering directly to the mill, sawmill or factory, according to a master plan, material of a predetermined character. 


\section{REFERENCES}

BAREFOOT, A. C., HITCHINGS, R.G., and E. L. ELLWOOD. 1964. Wood characteristics and kraft paper properties of four selected loblolly pines. I. Effect of fiber morphology under identical cooking conditions. Tappi 47:343-356.

EINSPAHR, D. W. 1964. Correlation between fiber dimensions and fiber and handsheet strength properties. Tappi 47:180-183.

FARRAR, J. L. 1961. Longitudinal variation in the thickness of the annual ring. For. Chron. $37: 323-330,349$.

GREEN, H. V. and J. WORRALL. 1963. Wood quality studies. Part I: A scanning microphotometer for automatically measuring and recording certain wood characteristics. Pulp \& Pap. Res. Inst. Can. Tech. Report 331.

KEEN, R. E. 1963. Weights and centres of gravity involved in handling pulpwood trees. Pulp \& Pap. Res. Inst. Can. Tech. Report 340.

KELLOGG, R. M. and F. F. WANGAARD. 1964. Influence of fiber strength on sheet properties of hardwood pulps. Tappi 47:361-367.

LARSON, P. R. 1963. Stem form development of forest trees. For. Sci. Monograph No. 5.

MITCHELL, H. L. 1964. Patterns of variation in specific gravity of southern pines and other coniferous species. Tappi 47:276-283.

NISSAN, A. H. and S. S. STERNSTEIN. 1964. Cellulose-fiber bonding. Tappi 47:1-6.

STEPHENS, G. R. 1963. Organic matter production in forests. Frontiers of Plant Sci., New Haven, 16:16-17.

VAN DEN AKKER, J. A., LATHROP, A. L., VOELKER, M. H., and L. R. DEARTH. 1958. Importance of fiber strength to sheet strength. Tappi 41:416-425.

YONEZAWA, Y., MURATA, T., KAYAMA, T., USAMI, K., TAKAMURA, N., and I. TAKANO. 1959. On the branches and top part of trees as the raw materials for pulp and fiberboard. Japan. Bull. For. Expt. Sta. No. 113:145-152.

YONEZAWA, Y., ITO, A., KIKUCHI, F., USAMI, K., TAKANO, I. and N. TAKAMURA. 1962. On the branches and top part of trees as the raw materials for pulp and fiberboard (2). Japan. Bull. For. Expt. Sta. No. 146:119-131.

YOUNG, H. E., GAMMON, C. B., and L. E. HOAR. 1963. Potential fiber from red spruce and red maple logging residues. Tappi 46:256-259. 